\title{
Vulnerability of infrastructure to natural hazards and climate change in China
}

\author{
Yi-Ming Wei $\cdot$ Ke Wang $\cdot$ Zhao-Hua Wang $\cdot$ Hirokazu Tatano
}

Received: 10 September 2014/Accepted: 10 September 2014/Published online: 23 September 2014

(C) Springer Science+Business Media Dordrecht 2014

Infrastructure is a lifeline system to ensure social and economic activities of a country. Disrupting infrastructure will directly result in the luxation of the social-economic chain and then destroy the upstream and downstream industry development. China, as a developing country, has been experiencing a high frequency of natural disasters in recent years, especially those disasters that occur affecting a wide area, high frequency and severe damage, such as earthquake, typhoon, flood, drought, and freezing. The most direct and serious loss brought by those disasters is considerable damage to infrastructure. At the same time, China's rapid economic development drives the fast growth of infrastructure construction, which also makes the newly constructed infrastructure significantly exposed to potential disasters. In addition, global warming and extreme climate events also severely affect the infrastructure of agriculture, industry, commerce, and energy systems in China. Therefore, it is important and indispensable to first analyze the vulnerability of infrastructure to natural disasters and climate change and then develop comprehensive approaches for disaster preparedness, mitigation, and recovery in China.

In this special issue, we collected 16 contributions on vulnerability assessment, risk and emergency management against natural hazards, climate change, and environment, energy, and carbon emission assessment-related issues in China. All of these research papers help to broaden recognition of the current situation of infrastructure vulnerability in China both at the national and regional levels and to promote understanding of the roles and applications of various techniques to model the effects of natural hazards, climate change and its

Y.-M. Wei $(\bowtie) \cdot$ K. Wang $\cdot$ Z.-H. Wang

Center for Energy and Environmental Policy Research, Beijing Institute of Technology, Beijing, China e-mail: wei@bit.edu.cn

Y.-M. Wei · K. Wang · Z.-H. Wang

School of Management and Economics, Beijing Institute of Technology, Beijing, China

H. Tatano

Disaster Prevention Research Institute, Kyoto University, Kyoto, Japan 
mitigation, energy saving, carbon emission reduction, and environmental protection efforts in China, so as to help policy design and public decision making.

For the vulnerability assessment at the national level, $\mathrm{Vu}$ and Noy contributed research on effect evaluation of natural disasters in China, and Liu and Wu provide a comparative assessment of energy supply vulnerability between China and the USA.

In $\mathrm{Vu}$ and Noy's research, the effects of natural disasters on income and investment in China were examined by using macroeconomic data and history of disaster exposure during the last 20 years. The relationship between the mortality and morbidity of disaster, economic damage, government investment, economic activity, and infrastructure development were described. Their research concluded that the aggressive investment of Chinese government in reconstruction after natural disasters enabled the government to prevent further deterioration in per capita incomes beyond the immediate aftermath of a disaster, and in addition, the Chinese government was effective at resource distribution across its extensive reach in the aftermath of large natural disasters.

In Liu and Wu's research, an energy supply vulnerability assessment index, with the consideration of the measurement of energy sustainability, stability, reliability, and diversification, was proposed, and based on which, the changes in energy supply vulnerability in China and the USA were assessed and compared over the period 2001-2010. They found that energy supply vulnerability in China fluctuated more than that in the USA. During 2001 and 2006, the vulnerability index of China increased quickly, but that presented a slowdown trend since 2007. In addition, compared with the USA, China faced higher maritime transportation and geopolitical vulnerability in energy supply. The policy implications for reducing energy supply vulnerability in China proposed by Liu and $\mathrm{Wu}$ are to develop a comprehensive energy supply system, controlling the growth of energy consumption and diversifying energy import.

For the vulnerability and risk assessment at the regional and local levels, six research papers separately analyzed the effects of climate change on runoff of upstream of Minjiang River, the risk of waterlog disaster of Huaihe River and the risk of ice flood disaster in Ningxia-Inner Mongolia Reach, the effects of marine disasters in Qingdao City, the spatiotemporal variation of meteorological droughts in Haihe River Basin, and the economic benefits of geo-hazard monitoring and warning engineering in the Three Gorges Reservoir areas.

Based on a SWAT model and nine climate scenarios, Huang et al. simulated and analyzed the effect of climate change on site runoff, watershed runoff depth, and evaporation of Minjiang River in China. Their analysis shows that during the last 50 years, the temperature increase and the precipitation decrease in the upstream of Mingjiang River are significant, and their simulation results showed that $20 \%$ variation in precipitation will lead to 28-32\% variation in runoff depth, and $2{ }^{\circ} \mathrm{C}$ variation in temperature will result in $1-6 \%$ variation in runoff depth, respectively. In addition, if temperature increases or decreases by $2{ }^{\circ} \mathrm{C}$, the potential evaporation will increase or decrease $5-16 \%$, respectively. They concluded that if the current trend of climate change continues into the future, extreme climate is most likely to occur as precipitation will decrease, temperature will rise, evaporation will increase, runoff will reduce, and drought will occur in the upper reaches of Minjiang River.

Focusing on the Huaihe River basin in Anhui province, Jin et al. developed an integrated risk system for waterlog disaster risk analysis. Their system could be divided into four subsystems for risk, vulnerability, disaster-reducing capacity, and disaster condition analysis. The fuzzy AHP and set pair analysis techniques were combined in the system for 
index-based integrated risk evaluation. The strong, medium, and weak risk areas in Huaihe River basin in Anhui were separately identified through their system.

Similarly, Wu et al. developed a comprehensive evaluation model for ice flood disaster risk analysis through projection pursuit, fuzzy clustering, and accelerating GA approaches. The process of risk identification, risk estimation, risk assessment, and risk management for ice flood disaster risk analysis of the upper Yellow River in Ningxia-Inner Mongolia reach was also proposed, and then, the ice flood disaster risk level of this area during 1991 and 2010 was evaluated. The evaluations' results could help the scientific decision making on ice flood prevention capability construction.

Extreme climate not only resulted in flood disasters but also led to droughts in China, which can affect large areas and cause severe environmental, social, and economic problems. He et al. examined the spatiotemporal variation of meteorological droughts in the Haihe River basin by using meteorological data-based comprehensive drought index from 44 stations over the past 50 years. Furthermore, the severity, duration, and frequency of each meteorological drought event were computed and analyzed, and based on which, He et al. concluded that the average drought duration was 57-85 days in each region of the Haihe River Basin over the 50 years study period, and during this period, drought occurred more than 0.95 times per year. The south branch of the Haihe River, Shandong Peninsula, and Bohai Bay suffered the most severe drought events, and the frequency of severe and extreme drought events had increased in the past 20 years.

Sometimes, natural hazards may occur as a consequence of man-made disasters. Some of the geo-hazards such as landslides that happened in the Three Gorges Reservoir area in China can be seen as an example. The completion and operation of the reservoir had increased the frequency of such geo-hazards in this area, and Chinese government has invested billions of funds in constructing an engineering system to effectively monitor and provide warning of geo-hazards in the Three Gorges Reservoir area. Yu et al. proposed an economic benefit assessment model for the evaluation of the investment returns of the monitoring and warning engineering system, and their model was applied to the case of Zhangjiawan landslide in Guojiaba Town of Zigui County in China. The evaluation results shown that, among various hazard-bearing bodies, land has the largest benefit (56.7 \%) in direct reductional loss, and agricultural production and ecological environment have the largest benefit $(97.6 \%)$ in indirect reductional loss. Furthermore, the benefits of hazard monitoring and warning engineering are significant: The ratios of expected return and the actual return are 1:280 and 1:37, respectively.

Located in the northeast coast of Shandong Province, the offshore areas of Qingdao City frequently suffered from marine disasters such as storm surge, ocean waves, sea ice, red tide, and harmful marine creature bloom which caused great economic losses and casualties in recent years. In Zhang et al.'s research, these marine disasters are divided into five categories as marine meteorological disasters, marine hydrological disasters, marine geological disasters, marine ecological disasters, and man-made marine disasters. Based on the scenario analysis, Zhang et al. proposed several optimizing countermeasures of marine disaster emergency management in Qingdao City which could help to reduce the inaccurate predictions and untimely early warnings of disasters and promote the social participation in the emergency management of marine disasters.

Other than the comprehensive evaluation and risk management of vulnerability to natural hazards and climate change, this special issue also collected several contributions focusing on the issues of carbon emissions, which is known as the source of climate change, and the issues of environmental performance. 
In Wang Zhaohua et al.'s two papers, the driving forces of carbon emissions from household consumption in China and the affecting factors to carbon emissions of energyintensive industries in China were detected. Their main findings include: (1) the largest indirect carbon emissions from Chinese household consumption turned from agriculture sector in 1992 into service sector in 2007; (2) the consumption level and the emission intensity were the main drivers influencing the change in indirect carbon emissions; and (3) industrial output is not the leading influencing factor to carbon emissions of energyintensive industries compared with the proportion of consumption of coal and electricity in the primary energy sector. Also focusing on the influencing factors of carbon emission in China, Fan et al. provided a specific analysis in petrochemical industries. Through LogMean Divisia Index method, they found that the most significant driving factor of carbon emissions in China's petrochemical industry is economic output effect, and industrial structural effect shows decreasing effect on carbon emissions during the period of 2000-2010. Compared with the $\mathrm{CO}_{2}$ emissions, the damages caused by the industrial pollutant emission and discharge are considered to be more serious in China. Therefore, in Wang Ke et al.'s research, the environmental efficiencies of industrial sectors of Chinese major cities were evaluated and discussed. Their evaluation results are quite positive: The industrial environmental efficiency increases in economically less developed regions were faster than in the well-developed regions, indicating that the inequitable nationwide industrial developments in China have started to alleviate.

At last, Wang Bing et al.'s bibliometric analysis provided us with an overview of climate change vulnerability based on the Web of Science data, and the global scientific performance and contemporary research topics in this field were summarized. Their analysis results showed that researches on climate change vulnerability have experienced a rapid growth since 2006. The top three topics in this research field were health issues in the socioeconomic system, food security issues in the agricultural system, and the issues of water resource management.

We are very glad to have been invited to become guest editors for the special issue of vulnerability of infrastructure to natural hazards and climate change in China. After a strict and long peer-review process, now is our privilege to provide this special issue. We do hope that this special issue will help the readers, practitioners, academics, and policy makers to understand the status of vulnerability to natural disasters and climate change in China and the efforts of climate change mitigation and disaster recovery in China. We thank all the authors, anonymous reviewers, editorial members, and staff for their efforts to make this special issue materialize. We also wish to extend our sincere thanks to professor Tad Murty, the editor-in-chief of Natural Hazards, for his support, invitation, and comments on this special issue. We gratefully acknowledge the financial support from the National Natural Science Foundation of China under Grant Nos. 71020107026, 71101011, and 71471018 . 